Gut, 1964, 5, 359

\title{
Watery diarrhoea and an islet cell tumour
}

\author{
W. HINDLE, D. J. McBRIEN, AND B. CREAMER \\ From St. Thomas' Hospital, London
}

EDITORIAL SYNOPSIS It is suggested that there are two hormonal syndromes associated with noninsulin-secreting islet cell tumours and this case is an example of the non-gastrin-secreting type with watery diarrhoea and hypokalaemia. The patient had histamine-fast achlorhydria and a normal gastric biopsy and no gastrin was recovered from the tumour tissue. The watery diarrhoea was isosmotic with plasma and was increased by an intravenous saline load. There was a dramatic response to steroids.

Since Zollinger and Ellison (1955) first described the syndrome of recurrent peptic ulceration, gastric hypersecretion, and an associated adenoma of the pancreatic islet cells, more than one hundred cases have been reported. Shortly after their original paper it was noticed that a number of these patients also had diarrhoea and that the diarrhoea was sometimes the presenting and outstanding symptom. Maynard and Point (1958) described one such patient in whom there was a gross excess of fat in the stools. They postulated that the steatorrhoea was the result of the inactivation of pancreatic enzymes at the low $p \mathrm{H}$ caused by the excessive gastric secretion and this hypothesis has received support from the work of Summerskill (1959) and Rawson, England, Gillam, French, and Stammers (1960). There seems little doubt that the gastric hypersecretion is due to the formation of a gastrin-like substance by the adenoma (Gregory, Tracy, French, and Sircus, 1962).

However, not all the patients with diarrhoea have had steatorrhoea (Priest and Alexander, 1957; Verner and Morrison, 1958) and recently cases have been described with hypochlorhydria and achlorhydria (Murray, Paton, and Pope, 1961 ; Parkins, 1961 ; Espiner and Beaven, 1962). It is clear that in these circumstances some other mechanism must be the cause of the diarrhoea. In a review of recent literature Sulman and Kirsner (1963), commenting on the report by Espiner and Beaven, state: 'The hypokalaemia and diarrhoea seemed attributable to an humoral agent of islet cell origin promoting the secretion of succus entericus. If additional cases of this type are identified, the entire concept of an humoral agent specifically stimulating gastric secretion will require modification to include a secretory stimulant also for the small intestine'.

This paper describes another such case, together with some observations on the faecal excretion of sodium and potassium and the response to treatment with steroids.

\section{CASE REPORT}

HISTORY AND EXAMINATION A man of 29 was admitted to hospital in May 1962 complaining of low backache and diarrhoea for nine months. The diarrhoea consisted of pale watery motions up to seven times in the 24 hours, usually with three or four stools at night. There had been no blood or mucus and no obvious fat in the stools but he was able to recognize food residues. He had lost about 2 st. in weight.

Apart from generalized wasting there were no abnormal physical signs.

RADIOLOGY A chest radiograph was normal. Lumbar spine radiographs showed only degenerative changes at the L. 1-2 level and the sacro-iliac joints appeared normal. A barium meal, small bowel meal, and barium enema were normal. In particular there was no evidence of peptic ulceration and no pancreatic calcification.

HAEMATOLOGY The haemoglogin was $82 \%(11.9 \mathrm{~g}$.) and E.S.R. $54 \mathrm{~mm}$. in one hour (Westergren). Serum $B_{12}$ was $250 \mu \mathrm{g} . / \mathrm{ml}$. and a Schilling test showed $8.4 \%$ of the ingested dose excreted in the urine in 24 hours.

BIOCHEMISTRY Plasma electrolytes on admission were: $\mathrm{Na} 132 \mathrm{mEq}$./l., K $3.2 \mathrm{mEq}$./l., Cl $99 \mathrm{mEq}$./l. Subsequent pre-operative estimations gave serum potassium levels of $2.9,3.0$, and $3.0 \mathrm{mEq} . /$. Blood urea was $22 \mathrm{mg} . \%$. Faecal fat estimation, from a five-day collection, was 6.4 g. in 24 hours. A glucose tolerance test was normal $(70,140,190,115,56 \mathrm{mg} . \%$ at 30-min. intervals). Plasma proteins were $8.5 \mathrm{~g} . \%$ (albumin $5.8 \mathrm{~g}$. and globulin $2.7 \mathrm{~g}$. $\%)$. Serum calcium was $10.6 \mathrm{mg} \%$ and phosphorus 4.9 mg. \% with alkaline phosphatase 24 K.-A. units. No 5 -hydroxyindole acetic acid was detected in the urine. A slight excess of FIGLU was present in the urine after the ingestion of $20 \mathrm{~g}$. histidine. 
GASTRIC FUNCTION AND HISTOLOGY An augmented histamine test meal was performed on two occasions and no free acid was found in the stomach. Gastric biopsy showed a normal mucosa with parietal cells present. Jejunal biopsy was normal.

LAPAROTOMY On 4 July 1962 a laparotomy was performed by Mr. H. E. Lockhart-Mummery. Some free fluid was present in the peritoneal cavity and a hard nodular mass the size of a cherry was found in the body of the pancreas. There were hard lymph nodes on the superior aspect of the pancreas leading up to the porta hepatis and multiple umbilicated nodules in both lobes of the liver. A finding of some interest was that both small and large bowel contained an abnormal quantity of fluid. A liver nodule was biopsied and histology showed an undifferentiated tumour which in some areas resembled pancreatic islet tissue. Special stains failed to demonstrate any granules but the specimen had been fixed in formalin. It was considered that he had a carcinoma of the pancreatic islet cells and a form of Zollinger-Ellison syndrome.

POST-OPERATIVE COURSE After the operation he continued to pour out vast quantities of watery faeces and required constant control of fluid and electrolyte intake. Data on the losses in urine and faeces during this period are presented in Figure 1.

It was clear that it would be impossible to continue the intravenous régime indefinitely and that death was likely to result from electrolyte depletion. In view of the partial success reported by Priest and Alexander (1957) it was decided to try the effect of cortisone. Cortisone, $50 \mathrm{mg}$. t.d.s., produced a dramatic change: the faecal volumes dropped to normal and the faeces became solid for the first time in 18 months (Fig. 2). The excess fluid and electrolytes were excreted in the urine. His general condition was also considerably improved. This improvement was not maintained by aldosterone ( $1 \mathrm{mg}$. $/ 24$ hours) or dexamethazone (4 mg./24 hours) although it was repeatedly shown with cortisone and prednisone. He began to sufier from abdominal and back pain and it was decided to treat him by radiotherapy to the liver and pancreas. A total dose of 3,035 r. was given. For the next few months he remained well apart from some backache; there was no diarrhoea provided that he continued to take prednisone.

In April 1963, he developed epilepsia partialis continua with a mild right hemiparesis and at this time he was found to have a right pleural effusion. His condition gradually deteriorated, and he died three months later.

\section{NECROPSY}

At necropsy multiple small nodules of growth were found over the peritoneal surface of the whole intestine and in the omentum. The liver surface was studded with small nodules and the liver substance contained numerous deposits. Tumour tissue was also present in the abdominal retroperitoneal, and anterior mediastinal lymph glands. Numerous small areas of growth were scattered over both pleurae and there was a large right pleural effusion.
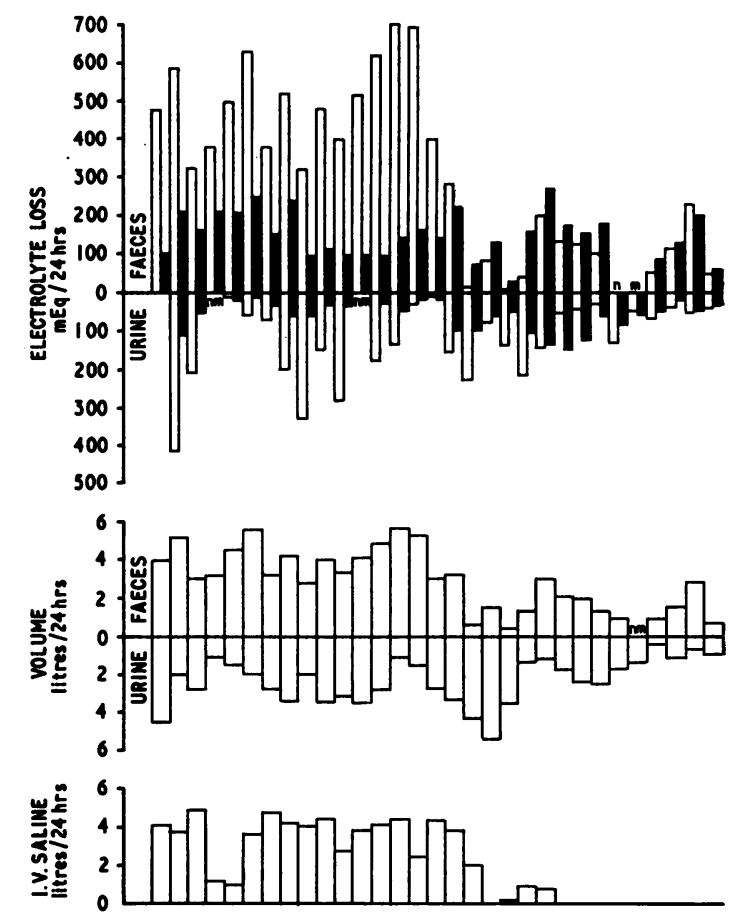

FIG. 1. Data on faecal and urinary volume and electrolyte losses, together with the volume of intravenous saline given each day. Each wide block represents a 24-hour period. The blocks showing electrolyte losses are divided into a clear area representing sodium excretion and a dark area representing potassium excretion.

$n \mathrm{~m}=$ not measured.

The pancreatic duct was dilated in its distal part to approximately four times its normal size. At the point of obstruction was a fibrous stricture, which may have resulted from the radiotherapy. Macroscopically no residual growth was found in the pancreas. There was a left-sided $4 \mathrm{~cm}$. diameter superior sagittal meningioma and considerable oedema of the underlying white matter. No macroscopic nodules of growth were found in the cranium or brain.

Histology of the pancreas at necropsy showed an undifferentiated small spindle-celled carcinoma; the appearances were compatible with a malignant isletcelled adenoma. Secondary carcinoma was found attached to the dura and adherent to the underlying brain, as well as in the liver, retroperitoneal tissues, testes, and lung.

Extracts of portions of the pancreatic and omental tumour tissue failed to yield any gastrin-like activity.

\section{DISCUSSION}

Murray et al. in 1961 reported a patient with watery diarrhoea and a pancreatic islet-cell adenoma 


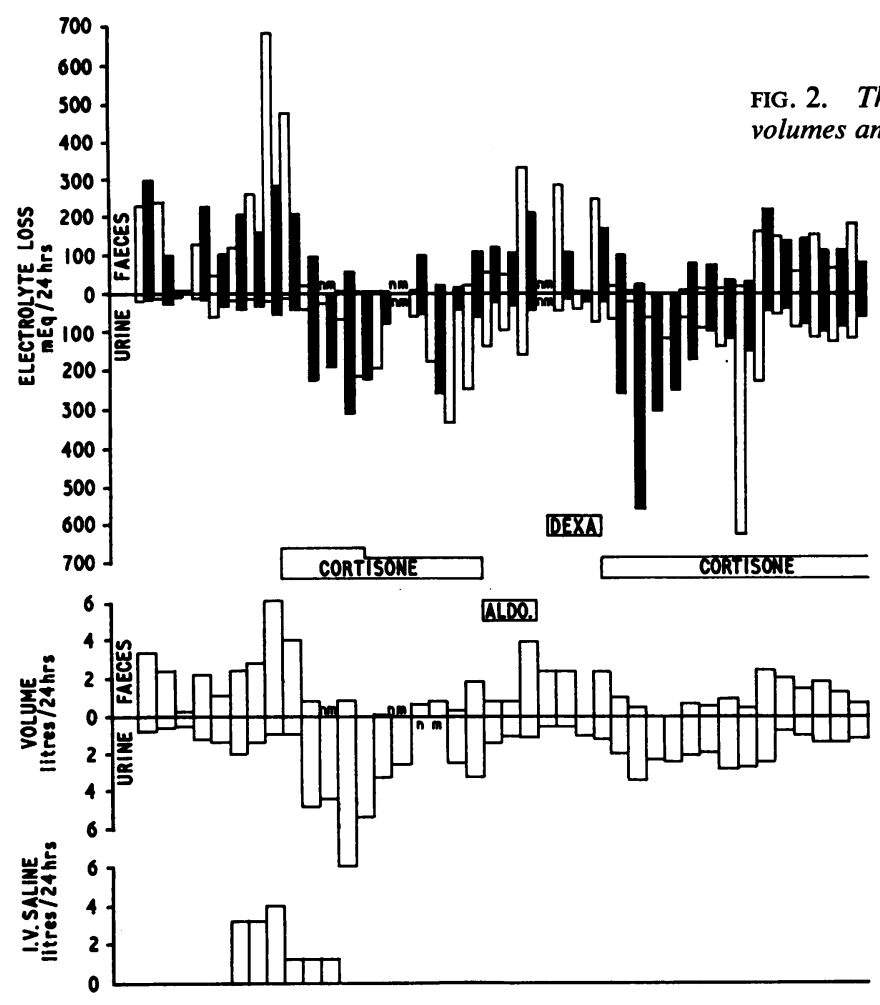

in whom there was no free acid in the stomach and in whom betazole hydrochloride produced only $15 \mathrm{mEq}$. $\mathrm{HCl}$ per litre. In the same year Parkins described a case in which only low acid curves were obtained in response to histamine stimulation.

Our case most closely resembles that described by Espiner and Beaven (1962). Both patients presented with severe watery diarrhoea associated with hypokalaemia. In neither case was there any evidence of duodenal or jejunal ulceration, neither had steatorrhoea, and in both there was a histaminefast achlorhydria. In both cases watery fluid was found in the lumen of the gut at laparotomy, and both were found to have a malignant islet cell carcinoma with secondary spread. We can find no other recorded cases of this syndrome associated with a histamine-fast achlorhydria.

Telling and Smiddy in 1961 first suggested that non-insulin secreting islet cell tumours of the pancreas might be responsible for more than one clinical syndrome and this case adds further support to such a differentiation. The first type is the classical gastrin-secreting tumour with hypersecretion of acid and peptic ulceration, as originally described by Zollinger and Ellison (1955). The second type, which is less common, is characterized by watery diarrhoea and hypokalaemia and is associated with hypochlorhydria or achlorhydria and no peptic ulceration. Gastrin has not been isolated from this type but a similar hormonal basis has been suggested to account for the condition (Telling and Smiddy, 1961). The findings in this case suggest an alteration of fluid and electrolyte transport in the gut together with inhibition of gastric secretion as normal parietal cells were present in the gastric biopsy. We have no direct evidence how these changes are produced or of the site involved, but the findings at laparotomy suggest that both the small intestine and the colon are implicated. The disturbance could as well be explained by an increase in the flux of water and electrolytes into the gut lumen as by a failure of reabsorption, or both.

Between these two distinct groups are a number of patients in whom peptic ulceration and hypersecretion of acid have been associated with profuse watery diarrhoea. It is possible that the symptoms in these cases are produced by the secretion of both hormones by the islet cell tumour.

Whatever the mechanism, the volume of faeces passed by these patients may be enormous with a gross associated sodium and potassium loss (Fig. 1), so that electrolyte balance becomes hazardous. The 

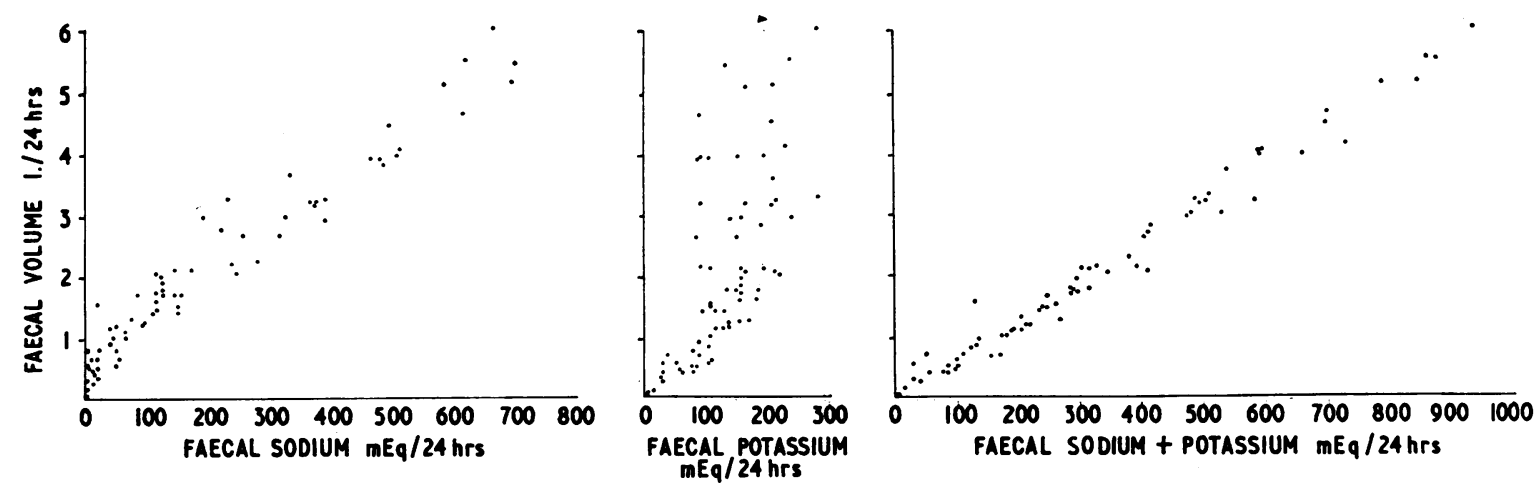

FIG. 3. The relationship between the excretion of sodium and potassium in the stools and the faecal volume.

loss of both sodium and potassium was related to the volume of faeces passed, though not in a linear fashion (Fig. 3). However, there is an exact linear relationship between the sum of sodium and potassium lost and the faecal volume. The faecal fluid was always isosmotic or nearly so. A similar observation was made in 1951 by Lubran and McAllen on the faecal electrolytes in ulcerative colitis.

In retrospect it was realized that the faecal volume was related in part to the volume of intravenous saline administered. Some of the huge faecal volume is then iatrogenic, for in this patient both the gut and the kidney appeared to be functioning as organs for the excretion of water and electrolytes. In relapse fluid and electrolyte was excreted mainly through the gut, in remission mainly through the kidney. The reciprocal relation of gut and kidney is well shown in Figure 2. Realization of this vicious circle of intravenous saline and diarrhoea may help in future instances.

Since 1957 a few patients with this syndrome have been treated with steroids and it was dramatically successful in the present case. It is of interest that this does not appear to be due to the mineralocorticoid action of cortisone for aldosterone did not have this effect. Similar observations were made by Parkins who noted that though his patient improved during pregnancy neither $9 \alpha$ fluorohydrocortisone nor chorionic gonadotrophins, ethisterone, or stilboestrol had any effect.
We wish to thank Prof. R. A. Gregory of Liverpool for assaying the tumour tissue for gastrin.

\section{REFERENCES}

Espiner, E. A., and Beaven, D. W. (1962). Non-specific islet-cell tumour of the pancreas with diarrhoea. Quart. J. Med., 31, 447-471.

Gregory, R. A., Tracy, H. J., French, J. M., and Sircus, W. (1960) Extraction of a gastrin-like substance from a pancreatic tumour in a case of Zollinger-Ellison syndrome. Lancet, 1, 1045-1048.

Lubran, M., and McAllen, P. M. (1951). Potassium deficiency in ulcerative colitis. Quart. J. Med, 20, 221-232.

Maynard, E. P., and Point, W. W. (1958). Steatorrhoea associated with ulcerogenic tumor of the pancreas Amer. J. Med., 25, 456-459.

Murray, J. S., Paton, R. R., and Pope, C. E., II (1961). Pancreatic tumor associated with flushing and diarrhoea. New Engl.J. Med., 264, 436-439.

Parkins, R. A. (1961). Severe watery diarrhoea and potassium depletion associated with an islet-cell tumour of the pancreas. Brit. med. J., 2, 356-357.

Priest, W. M., and Alexander, M. K. (1957). Islet-cell tumour of the pancreas with peptic ulceration, diarrhoea, and hypokalaemia. Lancet, 2, $1145-1147$.

Rawson, A. B., England, M. T., Gillam, C. G., French, J. M., and Stammers, F. A. R. (1960). Zollinger-Ellison syndrome with diarrhoea and malabsorption. Ibid., 2, 131-134.

Summerskill, W. H. J. (1959). Malabsorption and jejunal ulceration due to gastric hypersecretion with pancreatic islet-cell hyperplasia. Ibid., 1, 120-123.

Sulman, D., and Kirsner, J. B. (1963). Peptic ulcer. A review of recent literature. Gastroenterology, 44, 664-681.

Telling, M., and Smiddy, F. G. (1961). Islet tumours of the pancreas with intractable diarrhoea. Gut, 2, 12-17.

Verner, J. V., and Morrison, A. B. (1958). Islet cell tumor and a syndrome of refractory watery diarrhea and hypokalemia. Amer. J. Med., 25, 374-380.

Zollinger, R. M., and Ellison, E. H. (1955). Primary peptic ulcerations of the jejunum associated with islet cell tumor of the pancreas. Ann. Surg., 142, 809-728. 